\title{
AGROWISATA JAMBU DAN PENGEMBANGAN EKONOMI LOKAL DI KECAMATAN NGARGOYOSO KABUPATEN KARANGANYAR
}

\author{
Yoesti Silvana Arianti1), Yos Wahyu Harinta2) \\ 1), 2)Fakultas Pertanian, Jurusan Agribisnis, Universitas Veteran Bangun Nusantara, \\ Jl. Letjend S. Humardani No 1 Jombor Sukoharjo, Telp (0271) 593156, email: \\ ariantisilvana@gmail.com
}

\begin{abstract}
Abstrak
Tujuan dari penelitian ini adalah untuk mengetahui pengelolaan agrowisata jambu sebelum terjadi pandemic Covid-19 dan memberikan saran bagi pengelolaan dan penguatan agrowisata jambu setelah terjadi pandemic Covid-19 di Desa Jatirejo, Kecamatan Ngargoyoso, Kabupaten Karanganyar. Data yang digunakan dalam penelitian ini adalah data primer dan data sekunder. Data primer adalah data yang diambil langsung dari lokasi penelitian kawasan agrowisata jambu Ngargoyoso melalui pengamatan langsung di lokasi, wawancara dengan pengelola agrowisata, penyuluh, Dinas Pertanian, dan pengisian kuesisoner. Data sekunder adalah data yang diperoleh melalui instansi terkait dengan penelitian ini, baik tabulasi maupun deskriptif serta penelusuran literature. Penelitian ini memiliki empat tahapan, yaitu : (1) pengidentifikasian faktor internal dan eksternal, (2) melakukan analisis posisi bersaing agrowisata jambu biji merah, (3) merumuskan alternatif strategi yang dapat dijadikan masukan untuk penguatan agrowisata, dan (4) pemilihan alternatif strategi terbaik yang layak dan dapat dijalankan oleh seluruh stakeholder agrowisata jambu di Kecamatan Ngargoyoso, Kabupaten Karanganyar. Metode analisis data menggunakan analisis IFE, EFE, IE, SWOT dan QSPM. Hasil penelitian ini adalah Berdasarkan hasil analisis matriks IFE dan EFE didapatkan nilai masingmasing sebesar 2,85 dan 2,69. Hasil perhitungan dengan matriks IE menghasilkan posisi untuk agrowisata jambu di Kecamatan Ngargoyoso berada pada kuadran $\mathrm{V}$ dan strategi yang tepat untuk dijalankan adalah penetrasi pasar dan pengembangan produk. Alternatif strategi yang dihasilkan dari matriks SWOT sebanyak 10 strategi. Berdasarkan analisis QSPM, strategi yang menjadi prioritas dengan nilai TAS tertinggi sebesar 6,02 adalah melakukan kerja sama dengan pemerintah dan pihak lain untuk mendukung pemulihan agrowisata pasca terjadinya pandemic Covid-19.
\end{abstract}

Kata kunci: Agrowisata, Jambu, Pengembangan Ekonomi Lokal

\begin{abstract}
The purpose of this study was to determine the management of red guava agro-tourism before the Covid-19 pandemic and to provide advice for the management and strengthening of red guava agro-tourism after the Covid-19 pandemic in Jatirejo Village, Ngargoyoso District, Karanganyar Regency. Primary data is data taken directly from the research location of the Ngargoyoso red guava agro-tourism area through direct observation at the site, interviews with relevant stakeholders, and filling out questionnaires. Secondary data is data obtained through agencies related to this research, both tabulation and descriptive as well as literature searches. This research has four stages : (1) identifying internal and external factors, (2) analyzing the competitive position, (3) formulating alternative strategies that can be used as input for strengthening agrotourism, and (4) selecting alternative strategies best that is feasible and can be carried out by agro-tourism stakeholders. Methods of data analysis using IFE, EFE, IE, SWOT and QSPM. The results of this study are based on the results of the IFE and EFE matrix analysis, the values are 2.85 and 2.69. The results with the IE matrix in a position for guava agro-tourism in Ngargoyoso District in quadrant $V$ and the right strategy to implement is market penetration and product development. There are 10 strategy alternatives that are generated from the SWOT matrix. The QSPM analysis, the highest TAS value of the strategy that becomes a priority is to collaborate with the government and other parties to support the recovery of agro-tourism after the Covid-19 pandemic.
\end{abstract}

Keywords: Agro-tourism, Guava, Local Economic Development. 


\section{PENDAHULUAN}

Agrowisata saat ini banyak dikembangkan baik di Negara maju maupun Negara berkembang, salah satunya adalah di Indonesia. Agrowisata dapat memberikan tambahan pendapatan dan membuka kesempatan kerja bagi masyarakat pedesaan. Selain itu, konsep agrowisata meningkatkan pelestarian lingkungan sekaligus melestarikan adat budaya yang ada di masyarakat setempat (Yang, 2012).

Definisi agrowisata (agro tourism) adalah kolaborasi antara sector pariwisata dengan memanfaatkan potensi sector pertanian sebagai objek wisata, baik potensi berupa pemandangan alam kawasan pertaniannya maupun kekhasan dan keanekaragaman aktivitas produksi dan teknologi pertaniannya serta budaya masyarakat pertaniannya (Palit, et al., 2017 ; Priyono, 2016).

Banyaknya tanaman buah di sekitar hutan atau pemukiman warga adalah potensi yang dapat dikembangkan untuk penyelenggaraan agrowisata (Tanjungsari, el al., 2016). Salah satu prinsip pengembangan agrowisata yang berkelanjutan adalah adanya partisipasi masyarakat dalam proses perencanaan. Pengembangan partisipatif membutuhkan kerjasama yang baik antar stakeholder meliputi pemerintah, swasta dan masyarakat (Nurhidayati, 2015). Adanya kerjasama antar berbagai pihak tersebut diharapkan dapat menumbuh kembangkan pembangunan daerah. Peran pemerintah daerah yaitu hadir sebagai leader dan motor penggerak bagi perkembangan agrowisata (Kader dan Radjak, 2020).

Salah satu daerah di Indonesia yang memiliki pesona agrowisata yang sudah banyak dikunjungi oleh wisatawan domestic maupun internasional adalah Kabupaten Karanganyar. Keunggulan alam dan adat istiadat masyarakat yang masih mendarah daging membuat Kabupaten Karanganyar menjadi salah satu primadona untuk agrowisata di Provinsi Jawa Tengah.
Agrowisata yang banyak berkembang di Kabupaten Karanganyar adalah agrowisata jambu merah, yang daerah sentranya ada di Kecamatan Ngargoyoso. Hal ini dikarenakan jumlah pohon yang ditanam dan produksi jambu merah di Kecamatan Ngargoyoso mendominasi dibandingkan dengan kecamatan lain, yaitu sebesar 56,30 persen (Kabupaten Karanganyar dalam Angka, 2019).

Agrowisata jambu merah di Kecamatan Ngargoyoso, Kabupaten Karanganyar merupakan salah satu agrowisata yang terdampak adanya pandemic Covid-19 pada tahun 2020 ini. Dampak yang paling terlihat adalah jumlah wisatawan yang berkunjung ke agrowisata jambu berkurang dibandingkan dengan hari-hari biasanya. Jika hal tersebut tidak segera diatasi, maka penurunan jumlah pengunjung akan berpengaruh pula pada pendapatan masyarakat sekitar yang hidupnya bergantung dari agrowisata jambu biji merah.

Oleh karena itu, diperlukan diskusi untuk menghasilkan alternatif strategi yang dapat menguatkan pengelolaan agrowisata jambu biji merah di Kecamatan Ngargoyoso, Kabupaten Karanganyar terutama di era new normal ini. Diharapkan potensi yang ada di kawasan agrowisata tersebut dapat kembali bangkit dan menghasilkan keuntungan bagi masyarakat setempat, mendatangkan investor dan meningkatkan pendapatan daerah. Tujuan dari penelitian ini adalah mengetahui pengelolaan agrowisata jambu merah sebelum terjadi pandemic Covid-19 dan memberikan masukan (saran) terhadap pengelolaan dan pengembangan agrowisata jambu merah di Kecamatan Ngargoyoso, Kabupaten Karanganyar setelah terjadi pandemic Covid19.

\section{METODE PENELITIAN}

Penelitian ini dilakukan di Kecamatan Ngargoyoso, Kabupaten Karanganyar, Jawa Tengah. Lokasi penelitian dipilih dengan cara sengaja (purposive), dengan pertimbangan bahwa Kecamatan 
Ngargoyoso memang dijadikan tempat sentra produksi dan agrowisata jambu.

Penelitian ini menggunakan metode kualitatif deskriptif dengan pendekatan studi kasus. Metode ini dipilih agar peneliti dapat mengetahui dan mendeskripsikan pengelolaan agrowisata jambu di Kecamatan Ngargoyoso pra dan pasca terjadinya pandemic Covid-19. Diharapkan dengan adanya penelitian ini dapat diperoleh gambaran mengenai factor internal dan eksternal agrowisata serta dapat disusun dan diketahui strategi yang tepat dalam mengembangkan agrowisata jambu di Kecamatan Ngargoyoso berdasarkan skala prioritas yang dihasilkan. Pendekatan studi kasus dipilih agar peneliti dapat mengetahui secara mendalam tentang pengelolaan agrowisata jambu.

Data yang digunakan adalah data primer dan data sekunder yang diperoleh dari hasil observasi, wawancara, dokumentasi dan pengisian kuesioner. Analisis data yang dilakukan ada tiga tahap, yaitu : 1) tahap masukan (theinput stage), tahap pencocokan (thematching stage), dan tahap keputusan (thedecision stage) yang selengkapnya dijelaskan pada Tabel 1. Informan yang diwawancarai dalam penelitian ini adalah 1 orang penyuluh Kecamatan Ngargoyoso, 4 orang pengelola agrowisata, dan 1 orang pihak Dinas Pariwisata.

\section{HASIL DAN PEMBAHASAN}

\section{Analisis IFE dan EFE}

Faktor-faktor internal yang mempengaruhi perkembangan pengelolaan agrowisata jambu di Kecamatan Ngargoyoso dianalisis dengan Matriks IFE (Internal Factor Evaluation). Hasil penelitian menunjukkan bahwa faktor yang menjadi kekuatan adalah pihak agrowisata jambu yang menghimbau agar wisatawan menerapkan dan mematuhi protokol kesehatan. Agrowisata jambu yang perlahan-lahan mulai didatangi lagi oleh wisatawan membuat pihak manajemen (pengelola) agrowisata harus berbenah terutama untuk menjaga kenyamanan dan keselamatan bersama dengan menerapkan protokol kesehatan, yaitu mewajibkan pengunjung untuk memakai masker, pengecekan suhu tubuh oleh pihak agrowisata, dan rajin mencuci tangan.

Faktor yang menjadi kekuatan lainnya adalah terdapat paket wisata yang ditawarkan oleh pihak pengelola agrowisata jambu. Paket wisata yang ditawarkan bekerja sama dengan daerah wisata yang lain, yang memang sudah lama dilakukan oleh pengelola agrowisata. Selain itu, ada paket wisata yang ditawarkan di dalam kebun jambu yaitu petik jambu langsung dari kebun, melihat proses budidaya jambu biji (jambu merah), ada beberapa agrowisata yang memberikan cemilan untuk wisatawan (berupa es krim, keripik atau lainnya) serta ada spot foto yang dapat dimanfaatkan untuk pengunjung agar bisa berfoto.

Sementara itu, faktor yang menjadi kelemahan dalam pengelolaan agrowisata jambu terutama pasca pandemi Covid-19 adalah jumlah pengunjung yang berkurang drastis yaitu sekitar 40-50 persen.

Faktor lain yang menjadi kelemahan adalah promosi di media sosial yang kurang gencar. Ketika adanya pandemi Covid-19, banyak masyarakat yang enggan untuk melakukan kegiatan ke luar rumah atau bepergian ke luar daerah. Hal ini menyebabkan banyak usaha yang melakukan promosi dengan memanfaatkan jasa media sosial seperti Instagram, Facebook, Whatapp atau e-commers yang banyak berkembang di Indonesia, seperti Shopee, Lazada, Tokopedia.

Faktor-faktor eksternal yang tidak bisa dikendalikan oleh pihak pengelola agrowisata jambu dibedakan menjadi dua, yaitu peluang dan tantangan. Faktor yang menjadi peluang terbesar adalah 
permintaan buah jambu yang tergolong tinggi, terutama selama adanya pandemi. Hal ini dikarenakan masyarakat yang sudah mengetahui khasiat dari buah jambu yang mengandung banyak vitamin salah satunya adalah Vitamin $\mathrm{C}$ yang baik untuk menjaga imunitas tubuh.

Sedangkan yang menjadi ancaman terbesar adalah ada kebun yang berubah fungsi menjadi resort / restaurant. Hal ini dikarenakan banyak pihak agrowisata yang merasakan kerugian saat adanya pandemi Covid-19.

\section{Matriks IE}

Matriks IE terdiri dari 9 kuadran. Matriks IE didasarkan pada dua dimensi kunci yaitu skor bobot Matriks IFE total pada sumbu $x$ dan skor bobot Matriks EFE total pada sumbu $y$. Pada sumbu $x$ dari Matriks IE, skor bobot (David, 2017). Matriks IE adalah matriks yang dapat menunjukkan posisi pengelolaan agrowisata jambu di Kecamatan Ngargoyoso, Kabupaten Karanganyar saat ini. Hasil analisis dengan menggunakan Matriks IFE diperoleh skor 2,85 dan Matriks EFE dengan skor 2,69. Skor IFE dan IFE kemudian dimasukkan ke dalam Matriks IE dan kemudian ditarik garis vertikal dan horisontal sehingga ada titik pertemuan. Hasil analisis Matriks IE menunjukkan dari 9 kuadran yang ada posisi pengelolaan agrowisata jambu di Kecamatan Ngargoyoso, Kabupaten Karanganyar berada pada kuandran $\mathrm{V}$ seperti yang ada di Gambar 1, dimana posisi kegiatan tersebut berada pada pertahankan dan pelihara. Strategi yang dapat diterapkan adalah strategi yang intensif yaitu penetrasi pasar dan pengembangan produk (Azizah dan Rahmawati, 2020).

Strategi penetrasi pasar adalah memperluas pangsa pasar (market share). Pangsa pasar adalah bagian pasar yang dikuasai oleh pengelola agrowisata jambu atau prosentase penjualan yang dapat dipenuhi petani terhadap total penjualan para pesaing terbesarnya pada waktu dan tempat tertentu. Besarnya pangsa pasar setiap saat akan berubah sesuai dengan perubahan selera konsumen, atau berpindahnya minat konsumen, atau berpindahnya minat konsumen dari suatu produk ke produk yang lain (Setyorini, et al., 2016). Strategi penetrasi pasar yang dapat dilakukan oleh pihak agrowisata jambu di Kecamatan Ngargoyoso adalah dengan melakukan pemasaran yang gencar baik secara online maupun offline. Promosi online dapat dilakukan dengan hal yang sederhana misalkan dengan memanfaatkan media social yang dapat menjangkau banyak lapisan masyarakat di berbagai tempat pada satu waktu sehingga lebih efektif dan efisien.

Pengembangan produk dapat dilakukan dengan meningkatkan penjualan dengan cara memperbaiki atau memodifikasi produk dengan menghasilkan berbagai olahan yang berbahan baku jambu, daun jambu yang ada saat ini dan mempertahankan kualitas yang dihasilkan oleh petani jambu. Selain itu, pihak pengelola agrowisata juga dapat memberikan paket wisata yang lebih menarik bagi wisatawan. Hal ini sesuai dengan penelitian Budiarti, et al., (2013) yang mengembangkan agrowisata berbasis masyarakat di Kabupaten Bandung Barat dengan cara peningkatan usaha pengolahan produk hasil pertanian melalui pelatihan dan pembinaan dinas terkait (Dinas Perindustrian / UKM / Koperasi).

\section{Matriks SWOT}

Hasil dari matriks IE hanya menghasilkan alternatif strategi secara umum tanpa adanya implementasi strategi yang lebih teknis. Oleh karena itu, matriks IE dilengkapi dengan matriks SWOT yang merupakan langkah-langkah konkrit yang sebaiknya dilakukan oleh pengelola agrowisata berdasarkan pengembangan dari matriks IE. Tujuan lainnya adalah menghasilkan 
sebanyak mungkin kemungkinan alternative strategi yang dapat digunakan untuk perbaikan pengelolaan agrowisata jambu di Kecamatan Ngargoyoso, Kabupaten Karanganyar. Berdasarkan hasil analisis matriks SWOT yang ditampilkan pada Tabel 3 , diperoleh 10 alternatif strategi yang terdiri dari tiga alternative strategi $\mathrm{SO}$, tiga alternative strategi $\mathrm{WO}$, dua alternative strategi ST, dan dua alternative strategi WT.

\section{Analisis QSPM}

Berdasarkan hasil analisis matriks QSP pada pengelolaan agrowisata jambu di Kecamatan Ngargoyoso diperoleh 3 prioritas strategi yang dipilih oleh informan penelitian ini. Urutan prioritas strategi berdasarkan hasil nilai TAS (Total Attractiveness Score) yang tertinggi adalah sebagai berikut : 1) Melakukan kerja sama dengan pemerintah dan pihak lain untuk mendukung pemulihan agrowisata pasca terjadinya pandemic Covid-19, 2) Melakukan studi banding ke kawasan lain yang kegiatatan agrowisatanya lebih baik dan maju, dan 3) Memperluas pemasaran agrowisata dengan memanfaatkan media social.

Hasil analisis QSP yang memperoleh nilai TAS tertinggi yaitu sebesar 6,02 adalah melakukan kerja sama dengan pemerintah dan pihak lain untuk mendukung pemulihan agrowisata pasca terjadinya pandemic Covid-19. Strategi inilah yang dipilih untuk dijadikan prioritas daripada strategi-strategi yang lainnya. Agrowisata jambu termasuk salah satu agrowisata yang terdampak oleh pandemic Covid-19. Terjadi penurunan jumlah wisatawan yang berkunjung ke agrowisata tersebut. Namun, saat ini menyambut era new normal dimana masyarakat sudah diperbolehkan melakukan aktivitas di luar rumah sesuai dengan protocol kesehatan, mulai ada wisatawan yang berkunjung ke agrowisata. Proses peralihan dari era normal ke era new normal ini diperlukan kerja sama dengan berbagai pihak untuk mendukung pemulihan agrowisata.

Alternative strategi kedua yaitu Melakukan studi banding ke kawasan lain yang kegiatan agrowisatanya lebih baik dan maju dengan nilai TAS sebesar 5,84 dan tergolong cukup tinggi. Agrowisata jambu di Kecamatan Ngargoyoso belum menerapkan e-ticketing yang mulai banyak digunakan oleh pihak pengelola agrowisata lainnya. Inovasi ini diperlukan guna memudahkan wisatawan serta dapat mengurangi biaya untuk percetakan tiket. Tujuan dari studi banding ini adalah demi memperbaiki pengelolaan agrowisata jambu dan diharapkan jumlah wisatawan dapat terus bertambah di masa depan. Hal ini juga dilakukan oleh pihak agrowisata salak di Bali sesuai dengan penelitian Sumantra et al., (2015), dimana pemerintah Bali memfasilitasi bagi pihak pengelola agrowisata salak yang akan melakukan studi banding ke daerah lain.

Alternative strategi ketiga adalah memperluas pemasaran agrowisata dengan memanfaatkan media social yang mendapat nilai TAS sebesar 5,56. Penggunaan internet dan media social diharapkan bisa meningkatkan efisiensi dan efektivitas promosi yang dilakukan oleh pihak pengelola agrowisata. Wisatawan yang dapat dijangkau lebih luas, dengan biaya yang lebih hemat sehingga pihak pengelola perlu mengemas promosi produk dan jasanya sedemikian rupa agar tampil menarik.

\section{SIMPULAN}

Berdasarkan hasil analisis dan pembahasan pada penelitian ini maka kesimpulan yang dapat diambil sesuai dengan tujuan penelitian adalah sebagai berikut :

Berdasarkan hasil analisis tahap 1 yaitu dengan menggunakan matriks IFE dan EFE didapatkan nilai masing-masing sebesar 2,85 dan 2,69. Faktor yang menjadi 
kekuatan terbesar adalah pihak agrowisata yang menghimbau pada wisatawan agar mematuhi protokol kesehatan, sedangkan faktor yang menjadi kelemahan adalah berkurangnya jumlah wisatawan yang berkunjung akibat pandemi Covid-19. Analisis dengan matriks EFE menunjukkan peluang terbesar yang dapat dimanfaatkan adalah permintaan jambu selama pandemi termasuk tinggi, sementara tantangan yang timbul adalah adanya peralihan lahan / kebun menjadi resort / restaurant.

Hasil perhitungan pada tahap 2 dengan matriks IE menghasilkan posisi untuk agrowisata jambu di Kecamatan Ngargoyoso berada pada kuadran $\mathrm{V}$ dan strategi yang tepat untuk dijalankan adalah penetrasi pasar dan pengembangan produk. Alternatif strategi yang dihasilkan dari matriks SWOT sebanyak 10 strategi. Berdasarkan analisis QSPM, diurutkan dari nilai TAS tertinggi strategi yang menjadi prioritas adalah Melakukan kerja sama dengan pemerintah dan pihak lain untuk mendukung pemulihan agrowisata pasca terjadinya pandemic Covid-19, Melakukan studi banding ke kawasan lain yang kegiatatan agrowisatanya lebih baik dan maju, dan Memperluas pemasaran agrowisata dengan memanfaatkan media social.

\section{DAFTAR PUSTAKA}

Azizah, Nelly Nur dan Rahmawati, Farida. 2020. Strategi Pengembangan Agrowisata Melalui Pendekatan Quantitative Srrategic Plannong Matrix (QSPM). Edutourism Journal of Tourism Research, 2(1): 43-54.

Budiarti, Tati., Suwarto., Muflikhati, Istilaliyah. 2013. Pengembangan Agrowisata Berbasis Masyarakat pada Usahatani Terpadu Guna Meningkatkan Kesejahteraan Petani dan Keberlanjutan Sistem Pertanian. Jurnal IImu Pertanian Indonesia (JIPI), 18(3): 200-207.
David, Fred R. 2017. Manajemen Strategik: Konsep Suatu Pendekatan Keunggulan Bersaing. Salemba Empat. Jakarta.

Kader, A., \& Radjak, D. A. (2020). Pembangunan Ekonomi Masyarakat Melalui Agrowisata. Jurnal Inovasi IImu Sosial Dan Politik (JISoP), 2(1), 67-79.

Nurhidayati, S. E. (2015). Studi evaluasi penerapan Community Based Tourism (CBT) sebagai pendukung agrowisata

berkelanjutan. Masyarakat, Kebudayaan Dan Politik, 28(1), 1-10.

Palit, I. G., \& Rumagit, G. A. (2017). Strategi Pengembangan Kawasan Agrowisata Rurukan.Agri-Sosioekonomi,13(2A), 21-34.

Priyono, A., \& Astuti, W. (2016). Pengelolaan Agrowisata Buah Naga sebagai Wisata Alternatif di Lempongsari Sleman Yogyakarta. Kepariwisataan: Jurnal IImiah, 10(1).

Setyorini, Hany., Effendi, Mas'ud., Santoso, Imam. 2016. Analisis Strategi Pemasaran Menggunakan Matriks SWOT dan QSPM (Studi Kasus: Restoran WS Soekarno Hatta Malang. Industria : Jurnal Teknologi dan Manajemen Agroindustri, 5(1): 46-53.

Sumantra, I Ketut., Yuesti, Anik., Sudiana, AA Ketut. 2015. Pengembangan Model Agrowisata Salak Berbasis Masyarakat di Desa Sibetan. Jurnal Bakti Saraswati, 4(2): 156-168.

Tanjungsari, A., Cholis, A. F., Riung, C. Y., Rokani, L. E., \& Hakim, L. (2016). Analisis Potensi Agrowisata Buah di Wana Wisata Rawa Bayu, Desa Bayu, Kecamatan Songgon, Kabupaten Banyuwangi. Biotropika: Journal of Tropical Biology, 4(3), 67-72.

Yang, Li. 2012. Impact and Challenges in Agritourism Development in Yunnan, China. Journal Tourism Planning \& Development, 9(4) : 369-381. https://doi.org/10.1080/21568316.201 $\underline{2.726257}$ 


\section{Lampiran.}

Tabel 1. Tahapan dan Strategy Tools Penelitian

\begin{tabular}{lll}
\hline No & \multicolumn{1}{c}{ Tahapan } & \multicolumn{1}{c}{ Strategy Tools } \\
\hline 1 & Tahap Masukan (The Input Stage) & $\begin{array}{l}\text { Matriks IFE (Internal Factor Evaluation), } \\
\text { Matriks EFE (External Factor Evaluation) }\end{array}$ \\
2 & Tahap Pencocokan (The Matching Stage) & $\begin{array}{l}\text { Matriks SWOT (Strengths - Weaknesses - } \\
\text { Opportunities - Threats) }\end{array}$ \\
3 & Tahap Keputusan (The Decision Stage) & Matriks QSP (Quantitative Strategic Planning)
\end{tabular}

Sumber : David (2017)

Tabel 2. Matriks IFE (Internal Factor Evaluation)

\begin{tabular}{|c|c|c|c|c|}
\hline No & Faktor Kunci Internal & Bobot & Rating & Skor \\
\hline & Kekuatan (Strength) & & & \\
\hline 1 & Objek wisata yang ditawarkan bersifat rekreasi yang edukatif & 0,07 & 3 & 0,21 \\
\hline 2 & $\begin{array}{l}\text { Kebun jambu yang asri dan cocok digunakan sebagai tempat } \\
\text { untuk refreshing }\end{array}$ & 0,08 & 3 & 0,24 \\
\hline 3 & $\begin{array}{l}\text { Adanya petik jambu langsung dari kebun dan wisatawan dapat } \\
\text { langsung mengkonsumsinya }\end{array}$ & 0,08 & 4 & 0,32 \\
\hline 4 & Wisatawan dapat membeli bibit pohon jambu yang berkualitas & 0,05 & 3 & 0,15 \\
\hline 5 & $\begin{array}{l}\text { Terdapat paket wisata yang ditawarkan oleh pihak pengelola } \\
\text { agrowisata jambu }\end{array}$ & 0,11 & 4 & 0,44 \\
\hline 6 & $\begin{array}{l}\text { Pihak pengelola agrowisata jambu menghimbau agar } \\
\text { wisatawan menerapkan protokol kesehatan }\end{array}$ & 0,17 & 4 & 0,68 \\
\hline \multirow[t]{2}{*}{7} & $\begin{array}{l}\text { Banyak spot foto menarik yang dapat dimanfaatkan oleh } \\
\text { wisatawan }\end{array}$ & 0,08 & 4 & 0,32 \\
\hline & Kelemahan (Weaknesses) & & & \\
\hline 1 & Promosi melalui media sosial masih kurang gencar & 0,06 & 2 & 0,12 \\
\hline 2 & Terbatasnya dana dalam mengembangkan agrowisata & 0,03 & 2 & 0,06 \\
\hline 3 & Belum adanya e-ticketing bagi wisatawan & 0,10 & 1 & 0,10 \\
\hline 4 & $\begin{array}{l}\text { Belum banyak produk olahan jambu yang mampu dijual oleh } \\
\text { pihak pengelola agrowisata }\end{array}$ & 0,04 & 2 & 0,08 \\
\hline \multirow[t]{2}{*}{5} & $\begin{array}{l}\text { Berkurangnya wisatawan yang berkunjung ke agrowisata } \\
\text { akibat pandemi Covid-19 }\end{array}$ & 0,13 & 1 & 0,13 \\
\hline & & 1,00 & & 2,85 \\
\hline
\end{tabular}


Tabel 3. Matriks EFE (External Factor Evaluation)

\begin{tabular}{|c|c|c|c|c|}
\hline No & Faktor Kunci Eksternal & Bobot & Rating & Skor \\
\hline & \multicolumn{4}{|l|}{ Peluang (Opportunities) } \\
\hline 1 & $\begin{array}{l}\text { Lokasi agrowisata jambu yang dekat dengan tempat wisata } \\
\text { lainnya di Kabupaten Karanganyar }\end{array}$ & 0,09 & 3 & 0,27 \\
\hline 2 & $\begin{array}{l}\text { Terdapat dukungan pemerintah dalam mengembangkan } \\
\text { agrowisata }\end{array}$ & 0,08 & 3 & 0,24 \\
\hline 3 & $\begin{array}{l}\text { Adanya penyuluhan dari pemerintah pada agrowisata jambu } \\
\text { untuk menyediakan prasarana pendukung untuk mendukung } \\
\text { gerakan } 3 \mathrm{M}\end{array}$ & 0,12 & 4 & 0,48 \\
\hline 4 & $\begin{array}{l}\text { Permintaan buah jambu selama pandemic Covid-19 } \\
\text { termasuk tinggi }\end{array}$ & 0,17 & 4 & 0,68 \\
\hline \multirow[t]{2}{*}{5} & Harga jual jambu merah yang relatif tinggi & 0,11 & 4 & 0,44 \\
\hline & \multicolumn{4}{|l|}{ Tantangan (Threats) } \\
\hline 1 & Adanya persaingan dari komoditas lemon & 0,13 & 1 & 0,13 \\
\hline 2 & $\begin{array}{l}\text { Kondisi perekonomian yang tidak stabil karena pandemi Covid- } \\
19\end{array}$ & 0,15 & 1 & 0,15 \\
\hline 3 & $\begin{array}{l}\text { Adanya peralihan beberapa kebun menjadi resort / } \\
\text { restaurant }\end{array}$ & 0,08 & 2 & 0,16 \\
\hline 4 & $\begin{array}{l}\text { Pihak pengelola agrowisata belum banyak melakukan } \\
\text { kerjasama dengan pihak-pihak terkait untuk mengembangkan } \\
\text { agrowisata }\end{array}$ & 0,07 & 2 & 0,14 \\
\hline & & 1,00 & & 2,69 \\
\hline
\end{tabular}

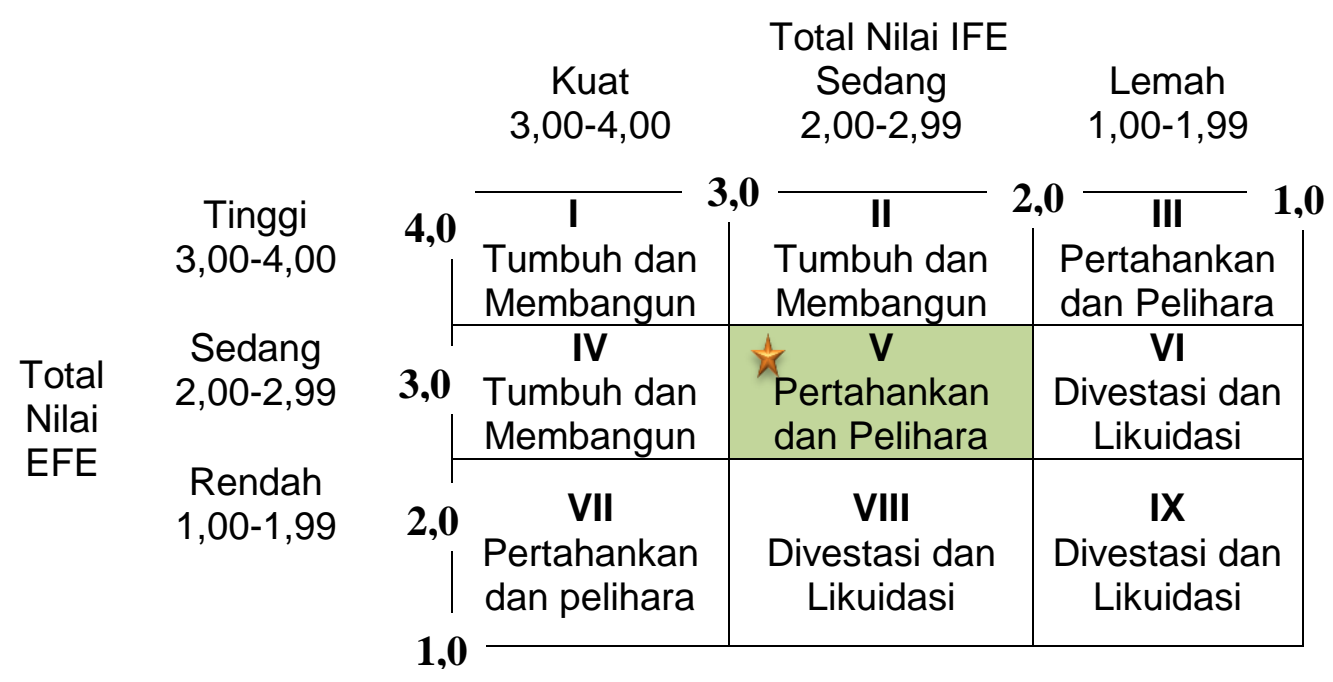

Gambar 1. Matriks IE 


\begin{tabular}{|c|c|c|}
\hline Faktor Eksternal & $\begin{array}{l}\text { KEKUATAN (Strengths) } \\
\text { 1. Objek wisata yang } \\
\text { ditawarkan bersifat rekreasi } \\
\text { yang edukatif } \\
\text { 2. Kebun jambu yang asri dan } \\
\text { cocok digunakan sebagai } \\
\text { tempat untuk refreshing } \\
\text { 3. Adanya petik jambu langsung } \\
\text { dari kebun dan wisatawan } \\
\text { dapat langsung } \\
\text { mengkonsumsinya } \\
\text { 4. Wisatawan dapat membeli } \\
\text { bibit pohon jambu yang } \\
\text { berkualitas pakn wisata yang } \\
\text { 5. Terdapat paket watar pihak } \\
\text { ditawarkan oleh } \\
\text { pengelola agrowisata jambu } \\
\text { 6. Pihak pengelola agrowisata } \\
\text { jambu menghimbau agar } \\
\text { wisatawan menerapkan } \\
\text { protokol kesehatan }\end{array}$ & $\begin{array}{l}\text { KELEMAHAN ( Weaknesses) } \\
\text { 1. Promosi melalui media sosial } \\
\text { masih kurang gencar } \\
\text { 2. Terbatasnya dana dalam } \\
\text { mengembangkan agrowisata } \\
\text { 3. Belum adanya e-ticketing bagi } \\
\text { wisatawan } \\
\text { 4. Belum banyak produk olahan } \\
\text { jambu yang mampu dijual oleh } \\
\text { pihak pengelola agrowisata } \\
\text { 5. Sarana transportasi umum } \\
\text { menuju agrowisata jambu } \\
\text { masih terbatas }\end{array}$ \\
\hline $\begin{array}{l}\text { PELUANG (Opportunities) } \\
\text { 1. Lokasi agrowisata jambu yang } \\
\text { dekat dengan tempat wisata } \\
\text { lainnya di Kabupaten } \\
\text { Karanganyar } \\
\text { 2. Terdapat dukungan } \\
\text { pemerintah dalam } \\
\text { mengembangkan agrowisata } \\
\text { 3. Adanya penyuluhan dari } \\
\text { pemerintah pada agrowisata } \\
\text { jambu untuk menyediakan } \\
\text { prasarana pendukung untuk } \\
\text { mendukung gerakan 3M } \\
\text { 4. Daya beli masyarakat untuk } \\
\text { membeli jambu tinggi selama } \\
\text { pandemic Covid-19 } \\
\text { 5. Harga jual jambu merah yang } \\
\text { relatif tinggi }\end{array}$ & $\begin{array}{l}\text { 1. Memanfaatkan dan } \\
\text { meningkatkan berbagai daya } \\
\text { tarik agrowisata jambu (S1, } \\
\mathrm{S} 2, \mathrm{~S} 3, \mathrm{~S} 5, \mathrm{O} 1, \mathrm{O} 2) \text {. } \\
\text { 2. Meningkatkan inovasi dalam } \\
\text { paket wisata agar wisatawan } \\
\text { lebih tertarik (S5, O2). } \\
\text { 3. Menjaga protocol kesehatan } \\
\text { demi kenyamanan bersama } \\
\text { (S6, O3, O4, O5). }\end{array}$ & $\begin{array}{l}\text { 1. Meningkatkan sarana dan } \\
\text { prasarana yang mendukung } \\
\text { pengembangan agrowisata } \\
\text { jambu (W2, W3, W5, O1, O2) } \\
\text { 2. Memperluas pemasaran } \\
\text { agrowisata dengan } \\
\text { memanfaatkan media social } \\
\text { (W1, W4, O4, O5). } \\
\text { 3. Bekerja sama dengan pihak } \\
\text { lain untuk mengadakan } \\
\text { pelatihan dalam pengolahan } \\
\text { buah jambu untuk } \\
\text { meningkatkan nilai tambah } \\
\text { (W4, O4, O5). }\end{array}$ \\
\hline $\begin{array}{l}\text { ANCAMAN (Threats) } \\
\text { 1. Adanya persaingan dari } \\
\text { komoditas lemon } \\
\text { 2. Kondisi perekonomian yang } \\
\text { tidak stabil karena pandemi } \\
\text { Covid-19 } \\
\text { 3. Adanya peralihan beberapa } \\
\text { kebun menjadi resort / } \\
\text { restaurant } \\
\text { 4. Pihak pengelola agrowisata } \\
\text { belum banyak melakukan } \\
\text { kerjasama dengan pihak-pihak } \\
\text { terkait untuk mengembangkan } \\
\text { agrowisata } \\
\text { 5. Berkurangnya wisatawan yang } \\
\text { berkunjung ke agrowisata } \\
\text { akibat pandemi Covid-19 }\end{array}$ & $\begin{array}{l}\text { 1. Melakukan kerja sama } \\
\text { dengan pemerintah dan } \\
\text { pihak lain untuk mendukung } \\
\text { pemulihan agrowisata pasca } \\
\text { terjadinya pandemic Covid- } \\
19 \text { (S5, S6, T2, T4). } \\
\text { 2. Memanfaat dengan } \\
\text { maksimal lahan yang masih } \\
\text { ada untuk ditanami jambu } \\
\text { yang berkualitas dan terjamin } \\
\text { kontinuitasnya (S4, S5, T1, } \\
\text { T3). }\end{array}$ & $\begin{array}{l}\text { 1. Melakukan studi banding ke } \\
\text { kawasan lain yang kegiatatan } \\
\text { agrowisatanya lebih baik dan } \\
\text { maju (W1, W3, T2, T4, T5). } \\
\text { 2. Membangun kesepakatan } \\
\text { dengan masyarakat agar tidak } \\
\text { menggantungkan hidupnya } \\
\text { hanya dari kedatangan para } \\
\text { wisatawan (W2, W4, T1, T2, } \\
\text { T5). }\end{array}$ \\
\hline
\end{tabular}




\begin{tabular}{|c|c|c|c|c|c|c|c|}
\hline \multirow{3}{*}{ Faktor-Faktor Utama } & \multirow{3}{*}{ Bobot } & \multicolumn{6}{|c|}{ Alternatif Strategi } \\
\hline & & \multicolumn{2}{|c|}{1} & \multicolumn{2}{|c|}{2} & \multicolumn{2}{|c|}{3} \\
\hline & & AS & TAS & AS & TAS & AS & TAS \\
\hline \multicolumn{8}{|l|}{ Kekuatan (Strength) } \\
\hline $\begin{array}{l}\text { 1. Objek wisata yang } \\
\text { ditawarkan bersifat } \\
\text { rekreasi yang edukatif }\end{array}$ & 0,05 & 3 & 0,15 & 4 & 0,20 & 2 & 0,10 \\
\hline $\begin{array}{l}\text { 2. Kebun jambu yang asri } \\
\text { dan cocok digunakan } \\
\text { sebagai tempat untuk } \\
\text { refreshing }\end{array}$ & 0,08 & 3 & 0,24 & 3 & 0,24 & 2 & 0,16 \\
\hline $\begin{array}{l}\text { 3. Adanya petik jambu } \\
\text { langsung dari kebun dan } \\
\text { wisatawan dapat } \\
\text { langsung } \\
\text { mengkonsumsinya }\end{array}$ & 0,11 & 3 & 0,33 & 4 & 0,44 & 3 & 0,33 \\
\hline $\begin{array}{l}\text { 4. Wisatawan dapat } \\
\text { membeli bibit pohon } \\
\text { jambu yang berkualitas }\end{array}$ & 0,03 & 3 & 0,09 & 3 & 0,09 & 3 & 0,09 \\
\hline $\begin{array}{l}\text { 5. Terdapat paket wisata } \\
\text { yang ditawarkan oleh } \\
\text { pihak pengelola } \\
\text { agrowisata jambu }\end{array}$ & 0,12 & 4 & 0,48 & 4 & 0,48 & 4 & 0,48 \\
\hline $\begin{array}{l}\text { 6. Pihak pengelola } \\
\text { agrowisata jambu } \\
\text { menghimbau agar } \\
\text { wisatawan menerapkan } \\
\text { protokol kesehatan }\end{array}$ & 0,15 & 4 & 0,60 & 3 & 0,45 & 4 & 0,60 \\
\hline \multicolumn{8}{|l|}{ Kelemahan (Weaknesses) } \\
\hline $\begin{array}{l}\text { 1. Promosi melalui media } \\
\text { sosial masih kurang } \\
\text { gencar }\end{array}$ & 0,10 & 2 & 0,2 & 2 & 0,2 & 1 & 0,1 \\
\hline $\begin{array}{l}\text { 2. Terbatasnya dana } \\
\text { dalam mengembangkan } \\
\text { agrowisata }\end{array}$ & 0,05 & 1 & 0,05 & 1 & 0,05 & 2 & 0,1 \\
\hline $\begin{array}{l}\text { 3. Belum adanya e- } \\
\text { ticketing bagi wisatawan }\end{array}$ & 0,10 & 2 & 0,2 & 2 & 0,2 & 1 & 0,1 \\
\hline $\begin{array}{l}\text { 4. Belum banyak produk } \\
\text { olahan jambu yang } \\
\text { mampu dijual oleh pihak } \\
\text { pengelola agrowisata }\end{array}$ & 0,08 & 1 & 0,08 & 2 & 0,16 & 3 & 0,24 \\
\hline $\begin{array}{l}\text { 5. Berkurangnya } \\
\text { wisatawan yang } \\
\text { berkunjung ke } \\
\text { agrowisata akibat } \\
\text { pandemi Covid-19 }\end{array}$ & 0,13 & 2 & 0,26 & 2 & 0,26 & 3 & 0,39 \\
\hline Sub Total I & 1,00 & & 2,68 & & 2,77 & & 2,69 \\
\hline \multicolumn{8}{|l|}{ Peluang (Opportunities) } \\
\hline $\begin{array}{l}\text { 1. Lokasi agrowisata } \\
\text { jambu yang dekat } \\
\text { dengan tempat wisata } \\
\text { lainnya di Kabupaten } \\
\text { Karanganyar }\end{array}$ & 0,09 & 4 & 0,36 & 2 & 0,18 & 2 & 0,18 \\
\hline
\end{tabular}


Agrisaintifika

Jurnal Ilmu-Ilmu Pertanian

Vol. 4, No. 2, 2020

Arianti \& Harinta. 2020

\begin{tabular}{|c|c|c|c|c|c|c|c|c|}
\hline \multirow{3}{*}{\multicolumn{2}{|c|}{ Faktor-Faktor Utama }} & \multirow{3}{*}{ Bobot } & \multicolumn{6}{|c|}{ Alternatif Strategi } \\
\hline & & & \multicolumn{2}{|c|}{1} & \multicolumn{2}{|c|}{2} & \multicolumn{2}{|c|}{3} \\
\hline & & & AS & TAS & AS & TAS & AS & TAS \\
\hline & $\begin{array}{l}\text { Terdapat dukungan } \\
\text { pemerintah dalam } \\
\text { mengembangkan } \\
\text { agrowisata }\end{array}$ & 0,08 & 3 & 0,24 & 2 & 0,16 & 3 & 0,24 \\
\hline 3. & $\begin{array}{l}\text { Adanya penyuluhan dari } \\
\text { pemerintah pada } \\
\text { agrowisata jambu untuk } \\
\text { menyediakan prasarana } \\
\text { pendukung untuk } \\
\text { mendukung gerakan 3M }\end{array}$ & 0,10 & 4 & 0,4 & 3 & 0,3 & 4 & 0,4 \\
\hline 4. & $\begin{array}{l}\text { Daya beli masyarakat } \\
\text { untuk membeli jambu } \\
\text { tinggi selama pandemic } \\
\text { Covid-19 }\end{array}$ & 0,17 & 4 & 0,68 & 4 & 0,68 & 4 & 0,68 \\
\hline 5. & $\begin{array}{l}\text { Harga jual jambu merah } \\
\text { yang relatif tinggi }\end{array}$ & 0,18 & 4 & 0,72 & 4 & 0,72 & 4 & 0,72 \\
\hline \multicolumn{9}{|c|}{ Tantangan (Threats) } \\
\hline & $\begin{array}{l}\text { Adanya persaingan dari } \\
\text { komoditas lemon }\end{array}$ & 0,13 & 2 & 0,26 & 1 & 0,13 & 3 & 0,39 \\
\hline 2. & $\begin{array}{l}\text { Kondisi perekonomian } \\
\text { yang tidak stabil karena } \\
\text { pandemi Covid-19 }\end{array}$ & 0,12 & 2 & 0,24 & 3 & 0,36 & 3 & 0,36 \\
\hline 3. & $\begin{array}{l}\text { Adanya peralihan } \\
\text { beberapa kebun } \\
\text { menjadi resort / } \\
\text { restaurant }\end{array}$ & 0,03 & 2 & 0,06 & 2 & 0,06 & 2 & 0,06 \\
\hline 4. & $\begin{array}{l}\text { Pihak pengelola } \\
\text { agrowisata belum } \\
\text { banyak melakukan } \\
\text { kerjasama dengan } \\
\text { pihak-pihak terkait untuk } \\
\text { mengembangkan } \\
\text { agrowisata }\end{array}$ & 0,1 & 2 & 0,2 & 2 & 0,2 & 3 & 0,3 \\
\hline \multicolumn{2}{|c|}{ Sub Total II } & 1,00 & & \begin{tabular}{|l|}
3,16 \\
5,84
\end{tabular} & & $\begin{array}{l}2,79 \\
5,56\end{array}$ & & $\begin{array}{l}3,33 \\
6,02\end{array}$ \\
\hline
\end{tabular}

